\title{
Lack of association of Endoglin insertion polymorphism in intracranial aneurysm in South Indian population
}

\author{
Linda V. Koshy, H. V. Easwer*, R. N. Bhattacharya*, Moinak Banerjee \\ Human Molecular Genetics Laboratory, Rajiv Gandhi Centre for Biotechnology, Thiruvananthapuram, *Department of Neurosurgery, Sree \\ Chitra Tirunal Institute for Medical Science and Technology (SCTIMST), Thiruvananthapuram, India
}

BACKGROUND: Endoglin, is a component of transforming growth factor- $\beta$ complex. It is involved in vascular development and structural maintenance of the vessel wall. Conflicting reports on the association of a six base insertion polymorphism in intron 7 of the endoglin gene in intracranial aneurysms (IA) have been reported earlier.

MATERIALS AND METHODS: A case-control study was designed to compare 102 South Indian patients with intracranial saccular aneurysms and 118 ethnically and geographically matched healthy controls. The frequency of the six base insertion polymorphism was assessed by heteroduplex analysis followed by direct sequencing.

RESULTS: Insertion allele count was 39 (19.1\%) of 204 alleles in the patient group and $42(17.8 \%)$ of 236 alleles in the control group. The INS allele frequency was similar to the frequency in Caucasian population, but it was significantly lower than the Japanese population $(P=0.01)$. There was also no relationship of this polymorphism in patients with single aneurysm (33/176 alleles) or those with multiple aneurysms (6/28 alleles).

CONCLUSION: Six base insertion polymorphism in Endoglin gene was not found to be a risk factor for intracranial saccular aneurysms in the South Indian population. Ethnic-related differences were observed. This is the first report on any genetic mutation in intracranial aneurysms in Indian population.

Key words: Association, endoglin, intracranial aneurysm, south indian, subarachnoid hemorrhage

\section{Introduction}

Intracranial aneurysm (IA [MIM 105800]) is a fairly common condition that is often asymptomatic until the time of rupture. Rupture of IA is the foremost cause for spontaneous subarachnoid hemorrhage (SAH), associated with high rates of morbidity and mortality. Incidence of IA in India varies from $0.75-10.3 \% .^{[1,2]}$ Cerebral arteries are particularly vulnerable to aneurysm formation since they lack an external elastic lamina.

These vessels shed most of their external supporting layers as they enter the skull and are considerably thinner and more fragile than vessels elsewhere in the body. The hemodynamic stress like high blood pressure and pulsations can lead to the formation of saccular aneurysms carrying a risk of rupture that varies with their location, size and wall thickness. ${ }^{[3]}$ Structural weakness of the arterial vessel wall may be due to genetic variants of genes responsible for the proper maintenance of vascular wall integrity. ${ }^{[4]}$ Risk factors, such as smoking and hypertension seem to predict fatal $\mathrm{SAH}$, independent of aneurysm size or patient age or Sex. ${ }^{[5]}$

Endoglin gene (ENG [MIM 131195]) codes for a homodimeric integral membrane glycoprotein, predominantly expressed on the vascular endothelium. ${ }^{[6]}$ The ENG gene is located on Chromosome 9q33-q34.1 and modulates angiogenesis and vascular development. Association of a six-base insertion (6bINS) in intron 7 of Endoglin gene remains inconclusive due to ethnic differences. ${ }^{[7-11]}$ In the present study we sought to investigate the association of the 6bINS (5'-TCCCCC3') polymorphism starting at $22 \mathrm{bp}$ distal from the 3' end of the exon 7 in the ENG gene as a risk factor for sporadic IA in an Indian population.

\section{Materials and Methods}

The study population consisted of 102 unrelated patients who had been consecutively admitted to a tertiary care referral hospital in South India during the period from May 2003 through January 2005. The diagnosis of aneurysm was done by cranial computed 
tomography (CT). The location of the aneurysm and its single or multiple nature was established by digital subtraction angiography (DSA). Patients with dissecting and fusiform aneurysms, arteriovenous malformations and hematological disorders were not included in the study. Clinical characteristics of patients with IA are summarized in Table 1. The patient group consisted of 54 males and 48 females; mean \pm SD age, $50.4 \pm 11.4$ years. The control group consisted of healthy, age and ethnically matched volunteers who did not possess any symptom of neurological disorders. Patients and controls belonged to the southern states of Kerala and Tamil Nadu with linguistic affiliation to Dravidian languages. The study was approved by the Institutional Ethical Committee for Biomedical Subjects, as per the ICMR guidelines.

\section{PCR amplification}

Three milliliters of peripheral venous blood from each patient was used for isolation of genomic DNA using the standard organic extraction protocol. Intron 7 region of the Endoglin gene was amplified by polymerase chain reaction using following primers 5 GAGGCCTGGCATAACCCT-3' and 5'GTGGCCACTGATCCAAGG-3'. [10] Genomic DNA (100

Table 1: Clinical characteristics of patients with intracranial aneurysm

\begin{tabular}{ll}
\hline Characteristics & Value \\
\hline No. of patients & 102 \\
Geographical location & South India (Kerala and Tamil Nadu) \\
Linguistic affiliation & Dravidian language (Malayalam and Tamil) \\
Mean age (range), y & $50.4(20-75)$ \\
Male, $\mathrm{n}$ & 54 \\
Mean age (range), y & $48.5(20-71)$ \\
Female, $\mathrm{n}$ & 8 \\
Mean age (range), y & $55.2(20-75)$ \\
SAH, $\mathrm{n}$ & 95 \\
Incidental, $\mathrm{n}$ & 7 \\
Location, $\mathrm{n}$ & \\
ACoA & 47 \\
MCA & 18 \\
ICA & 22 \\
Other & 17 \\
Multiple & 9 \\
Risk factors, $\mathrm{n}$ & \\
Smoking & 36 \\
Hypertension & 38 \\
Alcohol consumption & 20 \\
Diabetes & 7 \\
\hline
\end{tabular}

ng) was amplified using $10 \mathrm{pmol}$ of each primer, 250 $\mathrm{mM}$ deoxynucleotide triphosphate (Amersham), $1.9 \mathrm{mM}$ $\mathrm{MgCl}_{2}, 1 \mathrm{X}$ PCR buffer and $0.5 \mathrm{U}$ AmpliTaq Gold polymerase $(\mathrm{ABI})$. Amplifying conditions were as follows: initial denaturation at $94^{\circ} \mathrm{C}$ for four minutes, followed by 35 cycles of denaturation at $94^{\circ} \mathrm{C}$ for 30 seconds, annealing at $60^{\circ} \mathrm{C}$ for one minute and extension at $72^{\circ} \mathrm{C}$ for one minute by using a thermal cycler (BioRad).

\section{Heteroduplex analysis}

$10 \mathrm{ml}$ of each PCR product was denatured at $95^{\circ} \mathrm{C}$ for five minutes and slowly cooled $\left(1^{\circ} \mathrm{C} /\right.$ minute) to $37^{\circ} \mathrm{C}$ and were kept on ice until loading. The renatured samples were loaded along with $2 \mathrm{ml}$ of loading buffer ( $0.25 \%$ bromophenol blue, $0.25 \%$ xylene cyanol FF and $30 \%$ glycerol) in $12 \%$ nondenaturing polyacrylamide gel containing $1 \mathrm{M}$ urea and electrophoresed at room temperature in 1 X TBE buffer at $120 \mathrm{~V}$ for three hours and subsequently stained with ethidium bromide (0.5 $\mu \mathrm{g} / \mathrm{ml}$ ). The presence of the insertion in either the heterozygous or homozygous insertion genotype was revealed by the formation of heteroduplexes, which was absent in the homozygous wild type sequence.

\section{Cloning of the PCR product}

To confirm the nature of the insertion in the heterozygous state, the PCR product was purified with GFX Column (Amersham), cloned into a pGEMTvector (Promega) according the manufacturer's protocol and transformed into JM109 competent cells. Transformed colonies were selected by blue-white screening on LB agar plates containing Ampicillin $(100 \mu \mathrm{g} / \mathrm{ml})$. Colony PCR was done for the positive clones and the products were run on $1.2 \%$ agarose gel to confirm presence of 290 bp insert and analyzed by HA followed by DNA sequencing. This confirmed the presence of both wild type and insertion alleles, in an individual having heterozygous genotype.

\section{DNA sequencing}

The genotypes of all the cases and controls were further ascertained by sequencing. The PCR products were electrophoresed on a $1.2 \%$ agarose gel and bands were cut out and eluted for sequencing. Six micro liters of the eluted PCR product was used for sequencing 
using $0.64 \mathrm{mmol} / \mathrm{L}$ of the forward primer, used for genotyping. Cycling reactions conditions are as follows: for 25 cycles, ramp $\left(1^{\circ} \mathrm{C} /\right.$ second $)$ to $96^{\circ} \mathrm{C}$ for 10 seconds and ramp $\left(1^{\circ} \mathrm{C} /\right.$ second $)$ to $60^{\circ} \mathrm{C}$ for four minutes. Sequencing reactions were done using BigDye Terminator Cycle Sequencing v3.1 Kit and analyzed using ABI PRISM 310 Genetic Analyzer (Applied Biosystems). The homozygous wild type, heterozygous and homozygous insertion allele sequences were determined by sequencing [Figure 1].

\section{Statistical analysis}

Data was classified according to the genotypes of the Endoglin gene and the allele frequencies were calculated. Expected and observed frequencies of genotypes as well as Hardy-Weinberg proportions of allele distribution were assessed by Chi-square analysis. Comparison of genotypes between cases and controls were done using Armitage's trend test. Odds ratios with $95 \%$ confidence intervals were calculated on $2 \times 2$ contingency tables using GraphPad Prism Ver 4. Probability value $\leq 0.05$ was considered statistically significant. The power of the present study was calculated using the allele frequencies reported by

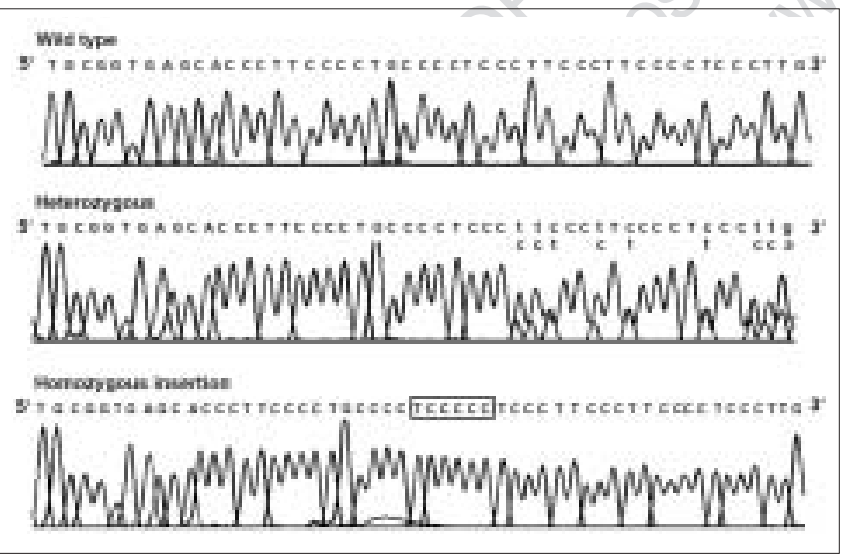

Figure 1: Six-base insertion polymorphism in position +22 of intron 7 of Endoglin gene
Takenaka et $a^{[6]}$ for the 6bINS polymorphism, at a $5 \%$ test level (alpha=0.05, two-tailed).

\section{Results}

We investigated the INS polymorphism in the ENG gene in 102 patients with intracranial saccular aneurysms (48 women and 54 men, aged 51.4 (SD 11.4) years). The control group was matched for age (mean: 49.9 (SD 12.8) years) and sex ratio (59 women and 59 men). Other features that coexisted with intracranial saccular aneurysm patients were hypertension in 38 patients $(37.3 \%)$, diabetes mellitus in seven $(6.9 \%)$, alcohol consumption in 20 (19.6\%) and active smokers in $36(35.3 \%)$. Nine patients manifested multiple aneurysms and as a result 116 aneurysms were observed in 102 patients. These aneurysms were localized as follows: anterior cerebral artery complex; 48 (41.4\%), internal carotid artery complex; 24 (20.7\%), middle cerebral artery complex; 21 (18.1\%) and vertebrobasilar artery complex; 23 (19.8\%). The insertion allele polymorphism was found in $39(19.1 \%)$ of 204 alleles in the patient group and in $42(17.8 \%)$ of 236 alleles in the control group. Allele frequencies did not differ significantly in the Indian IA patients versus controls $\left(\chi^{2}=0.13, \mathrm{df}=1, P=0.72\right)$. Genotype frequencies did not differ significantly between the sexes $(P=0.35)$. There was no significant difference in the allele and genotype frequencies between cases and controls [Table 2]. The $-/-,+/-$ and +/+ genotype frequencies in the control subjects were $67,30.5$ and $2.5 \%$ respectively and were very similar to those expected under Hardy-Weinberg equilibrium (67.6, 29.2 and $3.2 \%$, respectively, $\chi^{2}=0.216$, $P=0.89$ ). There was also no relation between patients who harbored single aneurysm and those who harbored multiple aneurysms for the INS allele; 33/176 (18.7\%) in the former and $6 / 28(21.4 \%)$ in the latter $(P=0.80)$.

Table 2: Allele and genotype frequency in the present case-control study

\begin{tabular}{|c|c|c|c|c|c|c|c|}
\hline \multirow[b]{2}{*}{ Group } & \multicolumn{3}{|c|}{ Allele } & \multicolumn{4}{|c|}{ Genotype } \\
\hline & - & + & Total & $-/-$ & $-/+$ & $+/+$ & Total \\
\hline \multicolumn{8}{|l|}{ Total } \\
\hline Control, n (\%) & $194(82.2)$ & $42(17.8)$ & 236 & $79(67.0)$ & $36(30.5)$ & $3(2.5)$ & 118 \\
\hline
\end{tabular}

Minus sign (-) indicates allele without 6bINS; (+), allele with 6bINS. 
Table 3: INS allele frequency reported in other populations.

\begin{tabular}{|c|c|c|c|c|c|c|c|}
\hline Ethinicity & Case & Control & Chi-square & $P$ value & OR & $95 \% \mathrm{Cl}$ & Reference \\
\hline South Indian & 0.191 & 0.178 & 0.1271 & 0.7214 & 1.092 & $0.6736-1.769$ & Present study \\
\hline Japanese & 0.409 & 0.273 & 7.523 & $0.0061^{*}$ & 1.809 & $1.182-2.769$ & 7 \\
\hline German & 0.145 & 0.141 & 0.01225 & 0.9119 & 1.029 & $0.6203-1.707$ & 8 \\
\hline N.American & 0.199 & 0.198 & 0.00087 & 0.9764 & 1.006 & $0.6608-1.533$ & 11 \\
\hline
\end{tabular}

${ }^{*} P$ value $<0.05$

The odds ratio of IA associated with the insertion allele was $1.09(95 \% \mathrm{Cl}, 0.674$ to 1.769$)$ and with the homozygous insertion genotype, $0.89(95 \% \mathrm{Cl}, 0.66$ to 2.08). We do observe ethnic differences in the prevalence of 6bINS allele frequencies in world populations [Table 3].

\section{Discussion}

This study is the first report on the role of the Endoglin gene polymorphism in Indian population. The present analysis demonstrated a power of $80 \%$ at a $5 \%$ chance of observing an association between the 6bINS and intracranial aneurysms. Multi-factorial diseases like IA are likely to involve a number of different contributing genes, which may harbor ethnic-related differences of genetic polymorphisms. In one of the earliest report the 6bINS polymorphism in the endoglin gene was reported to be associated with IA in Japanese population, where the INS allele polymorphism was $40.9 \%$ in the patient group and $27.6 \%$ in the control group $\left(\chi^{2}=7.48\right.$, $P=0.006) .{ }^{[7]}$ However, another study in the Japanese population failed to confirm the association, with the INS allele frequency at $30.2 \%$ in the patient group and $31.9 \%$ in the control group. In addition, a multipoint linkage analysis using 20 micro satellite markers spanning Chromosome 9 in 104 Japanese sib pairs showed no evidence of linkage in the vicinity of the Endoglingene. ${ }^{[9]}$ In a study conducted in the German population, an additional control group of healthy, unrelated Japanese volunteers were also analyzed and the INS allele frequency was found to be $33.3 \%$, i.e., 10 out of 30 alleles. ${ }^{[8]}$ From all the Japanese control groups analyzed independently in three different studies, it was seen that the INS allele frequency in the Japanese ranged from 27.6 to $33.3 \%$. This was nearly twice as high as those reported in the Germans (14.4\%), North American (19.8\%) and Polish (16.0\%) control groups. Although the frequency of the INS allele found in our study was similar to that reported in the Caucasian population, it was significantly lower when compared to the Japanese population $(P=0.01)$. This suggests that cross-cultural comparisons should be avoided for genetic association studies, as ethnic-related differences in the Endoglin gene exists, which may lead to wrong interpretation. Many factors influence contradictory findings across studies, which include measurement error with respect to genotyping and the behavioral phenotype, measurement error with respect to the phenotype, differences in designs and confounding variables such as population stratification. The threat of population stratification in the case-control design is often the scapegoat when an effect demonstrated in one study is not found in another.

\section{Conclusion}

Our results indicate ethnic differences in 6bINS allele frequencies when compared to other world populations but does not support the hypothesis that the 6bINS allele is associated with the development of intracranial saccular aneurysms or with any symptomatic aggressiveness of IA in South Indian population.

\section{Acknowledgments}

This study was supported by a fellowship from the University Grants Commission (UGC), New Delhi, India. LKV and HVE contributed equally to the research work.

\section{References}

1 Kapoor K, Kak VK. Incidence of intracranial aneurysms in north-west Indian population. Neurol India 2003;51:22-6.

2 Ramamurthi B. Incidence of intracranial aneurysms in India. J Neurosurg 1969;30:154-7.

3 Weir B. Aneurysms affecting the nervous system. Williams and Wilkins: Baltimore; 1987.

4 Juvela S. Prehemorrhage risk factors for fatal intracranial 
aneurysm rupture. Stroke 2003;34:1852-7.

5 Kataoka K, Taneda M, Asai T, Kinoshita A, Ito M, Kuroda R. Structural fragility and inflammatory response of ruptured cerebral aneurysms. A comparative study between ruptured and unruptured cerebral aneurysms. Stroke 1999;30:1396-401.

6 Ma X, Labinaz M, Goldstein J, Miller H, Keon WJ, Letarte $\mathrm{M}$, et al. Endoglin is overexpressed after arterial injury and is required for transforming growth factor-beta-induced inhibition of smooth muscle cell migration. Arterioscler Thromb Vasc Biol 2000;20:2546-52.

7 Takenaka K, Sakai H, Yamakawa H, Yoshimura S, Kumagai M, Yamakawa $\mathrm{H}$, et al. Polymorphism of the Endoglin gene in patients with intracranial saccular aneurysms. J Neurosurg 1999;90:935-8.

8 Krex D, Ziegler A, Schackert HK, Schackert G. Lack of association between Endoglin intron 7 insertion polymor- phism and intracranial aneurysms in a white population: Evidence of racial/ethnic differences. Stroke 2001;32:2689-94.

9 Onda H, Kasuya H, Yoneyama T, Hori T, Nakajima T, Inoue I. Endoglin is not a major susceptibility gene for intracranial aneurysm among Japanese. Stroke 2003;34:1640-4.

10 Pera J, Slowik A, Dziedzic T, Borratynska A, Rog TM, Betlej $\mathrm{M}$, et al. Endoglin gene insertion polymorphism not associated with aneurysmal subarachnoid hemorrhage. J Neurosurg 2005;102:879-81.

11 Peters DG, Kassam AB, Chang YF. A DNA sequence polymorphism in the Endoglin gene is not associated with intracranial aneurysm or aneurysmal subarachnoid hemorrhage. Cerebrovasc Dis 2005;20:96-100.

Source of Support: Nil, Conflict of Interest: None declared.

\section{Author Help: Online Submission of the Manuscripts}

Articles can be submitted online from http://www.journalonweb.com. For online submission articles should be prepared in two files (first page file and article file). Images should be submitted separately.

1) First Page File:

Prepare the title page, covering letter, acknowledgement, etc., using a word processor program. All information which can reveal your identity should be here. Use text/rtf/doc/pdf files. Do not zip the files.

2) Article file:

The main text of the article, beginning from Abstract till References (including tables) should be in this file. Do not include any information (such as acknowledgement, your names in page headers, etc.) in this file. Use text/rtf/doc/pdf files. Do not zip the files. Limit the file size to $400 \mathrm{~kb}$. Do not incorporate images in the file. If file size is large, graphs can be submitted as images separately without incorporating them in the article file to reduce the size of the file.

3) Images:

Submit good quality colour images. Each image should be less than $\mathbf{1 0 0}$ kb in size. Size of the image can be reduced by decreasing the actual height and width of the images (keep up to about 3 inches) or by reducing the quality of image. All image formats (jpeg, tiff, gif, bmp, png, eps, etc.) are acceptable; jpeg is most suitable. The image quality should be good enough to judge the scientific value of the image.

Always retain a good quality, high resolution image for print purpose. This high resolution image should be sent to the editorial office at the time of sending a revised article.

4) Legends:

Legends for the figures/images should be included at the end of the article file. 